\title{
A patient with a 30-year-old Björk-Shiley mechanical mitral valve without anticoagulation for 10 years
}

\author{
Ali Cemal Duzgun ${ }^{1}$, Ekin ilkeli \\ ${ }^{1}$ Cardiovascular Surgery, Ankara Training and Research Hospital, Ankara, Turkey \\ ${ }^{2}$ Cardiovascular Surgery, Duzce State Hospital, Duzce, Turkey
}

Kardiochirurgia i Torakochirurgia Polska 2021; 18 (2): 111-112

Today, a wide variety of mechanical mitral valves are implanted for mitral valve pathologies to replace native valves with cardiopulmonary bypass. Life-long use of anticoagulants is essential in mechanical valve patients. Otherwise, serious valve thrombosis leads to fatal outcomes. However, the risk of degeneration of mechanical valves is much lower compared to bioprosthetic valves [1].

We present the case of a 50-year-old female patient with a functional Björk-Shiley mechanical mitral valve who was not using anticoagulation for more than 10 years.

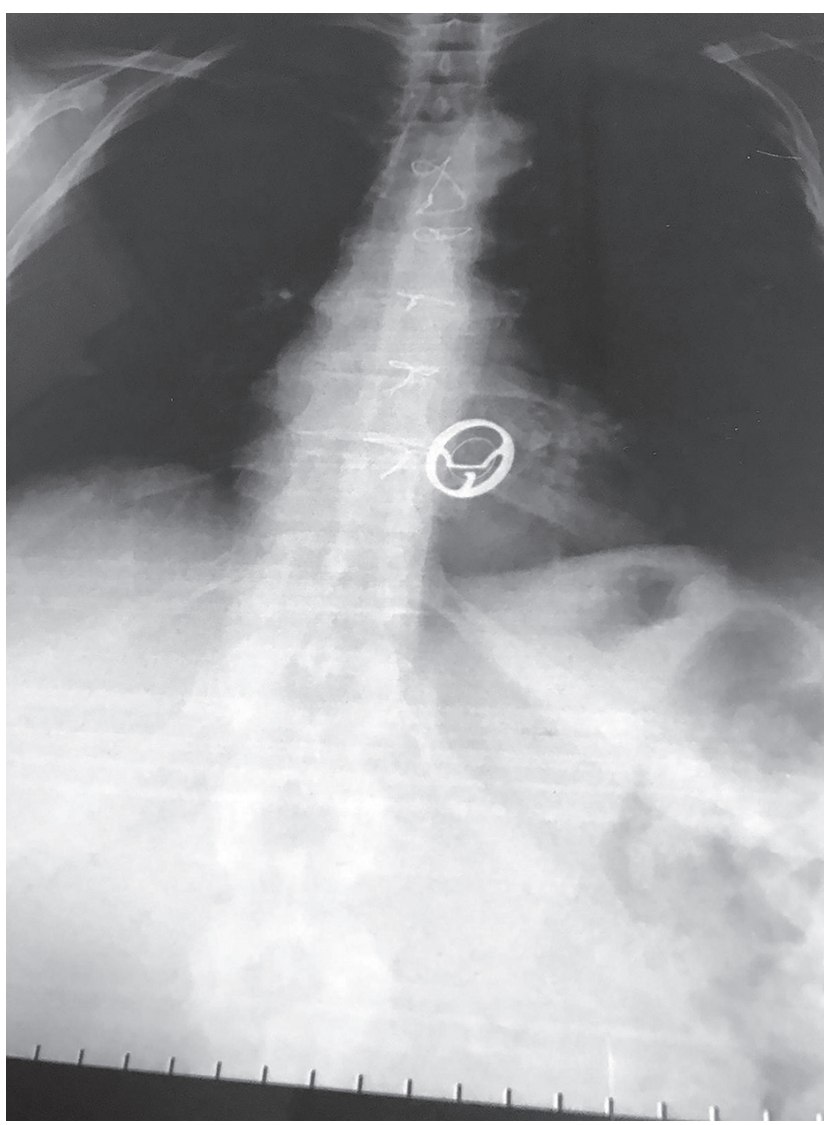

Figure 1. Björk-Shiley mechanical valve in normal position on telecardiography
A 55-year-old patient admitted to our clinic for routine examination had atypical non-cardiac complaints. The history revealed that the patient had undergone $21 \mathrm{~mm}$ Björk-Shiley mitral valve replacement in Hacettepe Medical Faculty 30 years ago. The patient was not on warfarin for 10 years. No neurological event had occurred. Examination revealed normal mechanical valve sounds. ECG, laboratory tests and chest X-ray were performed a priori. ECG showed normal sinus rhythm and the international normalized ratio (INR) was 1.2. Platelet (PLT) level was normal $\left(187 \times 10^{\%} / \mathrm{ml}\right)$. The patient said she had not previously consumed alcohol, used drugs or different food. The patient was on no diet at all. The initial liver biochemical profile was normal and the hepatitis $B$ and $C$ blood tests were negative. The patient had not been receiving any antiplatelet therapy. Chest $X$ ray revealed a single-leaflet valve in the natural position (Figure 1). Transthoracic echocardiography revealed an ejection fraction of 55\%, a mitral gradient of 10/6 and mild mitral regurgitation. No paravalvular leak was detected (Figure 2). The aortic, pulmonary and tricuspid valves were normal. The patient was started on warfarin.

The Björk-Shiley valves were first introduced in 1969. The first mechanical tilting single-leaf Björk-Shiley valves were made of formaldehyde acetal resin (Delrin). A durability of 50 years was initially anticipated but the valve mate-

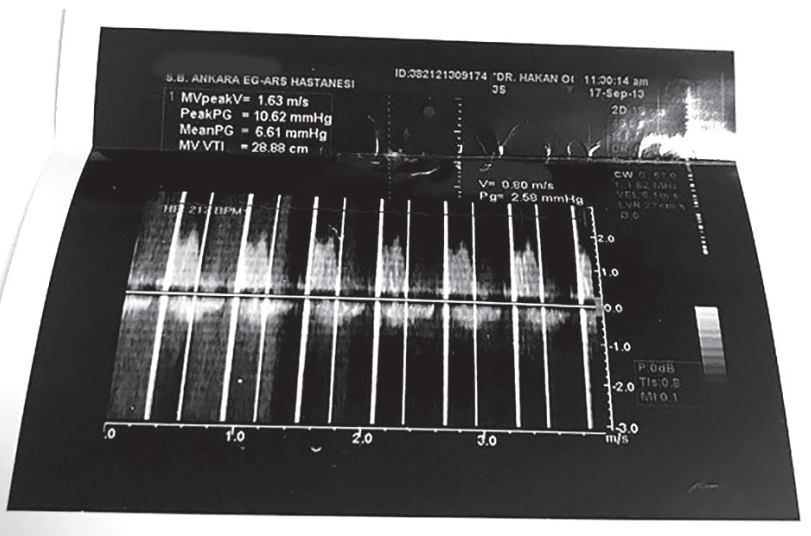

Figure 2. Functional mechanical valve on echocardiography

Address for correspondence: Dr Ekin Ilkeli, Department of Cardiovascular Surgery, Duzce State Hospital, Duzce, Turkey, phone: +90 5056384372, +90 38052913 00, fax: +90.380 54978 19, e-mail: ekinilkeli@hotmail.com Received: 12.02 .2021 , accepted: 18.02.2021. 
rial was replaced with pyrolytic carbon due to the observed deformations [2].

Warfarin plays a very important role in the treatment of patients with valve replacement. If optimal INR is not provided, it is reported to cause major valve events such as associated bleeding and thrombosis [3].

The most common important problem with mechanical valves is the use of anticoagulants for a long time. Currently, all patients receive anticoagulant treatment after standard mechanical valve replacement. The INR test is used to determine whether adequate anticoagulation has been achieved. In the literature, serious fatal complications were reported in patients discontinuing anticoagulants after mechanical valve replacement as well as cases without complications. The absence of complications was attributed to chance and genetic variations [4].

It is a priority to provide and maintain a consultancy service evaluating individual habits and examining the factors leading to nonadherence in addition to the drug dose. It is reported that if the patients are poorly educated they discontinue anticoagulants depending on the educational level of populations and develop serious complications [5, 6].

Studies have shown that following treatment use of warfarin has been linked with an overall decrease in bleeding and thromboembolic compounds and superior longterm survival. However, many warfarin patients do not know which foods contain high levels of vitamin $\mathrm{K}$ and are therefore vulnerable to bleeding episodes [7, 8].

Based on our experience, the most important reasons for warfarin discontinuation are the educational status of the patients, social habits and inadequacy of our institutional patient follow-up systems. The absence of complications or maintained function of the valves despite the longterm nonuse of anticoagulants in patients with mechanical valves should be evaluated in a separate study.

\section{Disclosure}

The authors declare no conflict of interest.

\section{References}

1. Head SJ, Çelik M, Kappetein AP. Mechanical versus bioprosthetic aortic valve replacement. Eur Heart J 2017; 38: 2183-91.

2. Masumoto H, Shimamoto M, Yamazaki F, Nakai M, Fujita S, Miura Y, Itonaga T, Ito $\mathrm{H}$. A case report of valve dysfunction associated with abrasion of the delrin disk used in early Björk-Shiley mitral valves requiring resurgery. Ann Thorac Cardiovasc Surg 2009; 15: 126-8.

3. Emery RW, Emery AM, Raikar GV, Shake JG. Anticoagulation for mechanical heart valves: a role for patient based therapy. J Thromb Thrombolysis 2008; 25: $18-25$.

4. Salmane C, Pandya B, Lafferty K, Patel NJ, McCord D. Longest Event-free survival without anticoagulation in a mechanical aortic valve replacement. Clin Med Insights Cardiol 2016; 10: 47-50.

5. Ciuruś T, Cichocka-radwan A, Lelonek M. Factors affecting the quality of anticoagulation with warfarin: experience of one cardiac centre. Kardiochir Torakochir Pol 2015; 12: 334-40.

6. Kankaya EA, Bilik Ö. Kalp kapak protezleri sonrası antikoagülan tedaviye Uyum. Turk J Cardiovasc Nurs 2018; 9: 29-34.

7. Watt TMF, Murray SL, Brescia AA, Burn DA, Wisniewski A, Khan SP, Romano MA, Bolling SF, The Michigan Mitral Research Group Mmrg. Anticoagulation following mitral valve repair. J Card Surg 2020; 35: 2887-94.

8. Rangecroft A, Prabhu SS, Huang CC. Pickles and warfarin interaction: a casebased review. Clin Rheumatol 2020; 40: 1621-4. 